\title{
¿QUÉ SIGNIFICA ACTUAR POR UN FIN? LA RESPUESTA DE FRANCISCO SUÁREZ EN EL MS DE BEATITUDINE (1579) Y EN EL TRATADO DE ULTIMO FINE HOMINIS (1628)*
}

\author{
ROSA COLMENAREJO FERNÁNDEZ \\ Universidad Loyola Andalucía (España) \\ PAULA OLIVEIRA E SILVA \\ Universidade do Porto (Portugal)
}

\begin{abstract}
RESUMEN: La influencia de la obra y doctrina de Francisco Suárez (Granada, 1548-Lisboa, 1617) en la conformación del pensamiento moderno ha sido ampliamente estudiada en áreas como la filosofía política y del derecho, la metafísica o la epistemología. Sin embargo, la filosofía moral de Suárez, en concreto aquella que, como él mismo explica, habrá de servir de base a sus tratados de teología moral, está todavía por analizar. El objetivo de este trabajo es traer a luz algunos aspectos de la teoría suareciana sobre la causalidad final en los agentes libres, confrontando su doctrina sobre la causalidad del fin en dos comentarios, escritos en distintos períodos, a las cuestiones I-Ilae de la Suma de Teología de Tomás de Aquino: el manuscrito inédito De beatitudine (1579) y el tratado De ultimo fine hominis, publicado por Baltasar Álvares (1628). La cuestión aquí analizada - qué significa actuar por un fin - se asume como un instrumento heurístico para dar a conocer sea estas dos fuentes estudiadas, sea el interés filosófico de las doctrinas de Suárez a respecto de la causalidad final. Las conclusiones apuntan a los siguientes aspectos: i) la proximidad, aun con dudas, de Suárez a la doctrina tomista de la causalidad del fin, en el comentario de 1579; ii) la asunción parcial de la doctrina tomista en cuanto a la función del intelecto en el actuar libre, y la afirmación de que el locus finis es la voluntad, en el comentario de 1628. Trabajando con estos matices hemos querido establecer algunos puntales de encuentro que permitan hacer visibles los puentes que emergen entre una tradición escolástica que enfrenta una nueva imagen del hombre, y la filosofía moral inmediatamente posterior que despojando aquella de su fundamento teológico, avanza con paso firme hacia la modernidad.
\end{abstract}

PALABRAS CLAVE: Francisco Suarez; causalidad final; actuar humano; razón; voluntad.

\section{What is "to act for an end»? Francisco Suarez' answer in the ms De beatitudine (1579) and in De ultimo fine hominis (1628)}

ABSTRACT: The influence of the work and teaching of Francisco Suárez (Granada, 1548-Lisbon, 1617 ) in the shaping of modern thought has been widely studied in areas such as political philosophy and law, metaphysics, and epistemology. However, the moral philosophy of Suarez, in particular that which, as he himself explains, was needed as a basis for his moral theology, has yet to be analyzed. In this paper, we propose to elucidate some aspects of Suarez's theory of human agency final causality. We compare two of his commentaries, from different periods, on the I-llae of Thomas Aquinas' Summa theologiae: the unpublished manuscript De beatitudine (1579) and Suarez's treatise De ultimo fine hominis, the first of five treatises on morality posthumously published by Baltasar Álvares (1628). The

Este trabajo está financiado por un proyecto de investigación I+D+i del Ministerio de Economía y Competitividad del Gobierno de España y el Fondo Europeo de Desarrollo Regional (FEDER). Código de proyecto FFI2015-64451-R (MINECO/FEDER, UE): «Pensamiento y tradición jesuita y su influencia en la modernidad desde las perspectivas de la historia, la traductología y la filosofía jurídica, moral y política». Investigador principal: Juan Antonio Senent de Frutos. 
question analyzed here, the nature of final causality, is assumed as a heuristic instrument to acquaint readers with both the sources studied and the philosophical import of Suárez' doctrine on morality. The findings suggest the following: i) the closeness, still with doubts, of Suárez' 1579 commentary to Thomas' doctrine of human agency final causality; (ii) in the 1628 commentary, his partial assumption of Thomas' doctrine on the role of intellect in free choice, and his clear determination in the assertion that the locus finis is the will. Working with these nuances, we illustrate some connection points that show both how 16th century scholasticism deals with philosophical tradition to explain a new image of man, and how subsequent moral philosophy is influenced by these theories while rejecting their theological foundation.

KEY WORDS: Francisco Suárez; final causality; human action; reason; will.

\section{La FILOSOFía MORAL de SuÁREZ: IMPORTANCIA y ESTAdo DEL ARTE}

Francisco Suárez (Granada, 1548-Lisboa, 1617) es uno de los nombres más notables de la filosofía y de la teología producida en el período designado por escolástica ibérica o peninsular. Por la importancia de su obra y doctrinas en áreas decisivas para la historia de la filosofía y de la teología, como son la filosofía política y del derecho, la metafísica y teoría del conocimiento, su obra es hoy relativamente bien conocida y documentada, sea por ediciones en lenguas modernas, sea por los numerosos estudios que desde hace más de cien años la comunidad académica le viene dedicando ${ }^{1}$. La comunidad científica internacional viene tomando cada vez mayor conciencia de la influencia decisiva de las doctrinas filosóficas producidas en la península ibérica en el siglo XVI en la conformación de la estructura mental que designamos como modernidad, como testimonia la profusión de estudios que hoy están disponibles para este período, unos más focalizados en la comprensión del contexto histórico y doctrinal, otros de matriz más exegética y hermenéutica.

En lo que se refiere a las doctrinas filosóficas de Suárez, están hoy disponibles estudios sea de contextualización general de su obra y doctrinas, sea de especialidad privilegiando su metafísica, filosofía del derecho o sus doctrinas sobre filosofía y psicología del hombre, siendo estos los dominios que han despertado más interés por parte de los académicos, justamente por la influencia en particular en la filosofía de los siglos XVII y XVIII². Sin embargo,

1 Referencias bio-bibliográficas detalladas pueden consultarse en Scholasticon (JACOB Schmutz ed.): http://scholasticon.ish-lyon.cnrs.fr/Information/Suarez_fr.php (Accedido 19/07/2017). Una cronología de los marcos principales de su vida y obra se puede leer en F. Suárez. As Paixões da Alma/ Las Pasiones del Alma. Ed. Trilingue latim, português, castelhano. Coleção Imago Mundi 13. Porto, Ed. Afrontamento, 2014 pp. 33-35. Para una síntesis biográfica de Suárez en el contexto histórico y doctrinal del siglo XVI vid. HiLl, B., «Introduction», in Hill, B. \& Lagerlund, H. (eds.), The Philosophy of Francisco Suárez, Oxford University Press, Oxford, 2012, pp. 13-21.

2 Vid., entre otras, las siguientes obras colectivas cuyos estudios aportan información importante para una mejor comprensión de este período de la historia de la filosofía, sobre todo en lo que se refiere a la relación entre el aristotelismo de matriz escolástica y la modernidad: Hill, B. \& Lagerlund, H. (eds.), The Routledge Companion to the Sixteenth 
la filosofía moral de Suárez, en concreto aquella que, como él mismo explica, habrá de servir de base a sus tratados de teología moral, está todavía por analizar como mantiene Penner siendo él mismo uno de los académicos que ha prestado atención a este tópico de la filosofía suareciana ${ }^{3}$.

Por otra parte, los estudios sobre filosofía moral de Suárez han abordado la cuestión de la acción moral de un modo generalmente orientado por el derecho natural y la justicia ${ }^{4}$. O bien, analizan la cuestión de la causalidad de los agentes libres a partir de la exposición que deja planteada el mismo Suárez en su Disputación Metafísica XIX, como lo hace el propio Penner ${ }^{5}$, aunque sea un buen conocedor de los Tratados de Moral de Suárez, pues ha traducido parte de esta obra a inglés. Desde esta misma perspectiva se constituye el estudio de Erik Åkerlund ${ }^{6}$, que analizó este tema en su tesis doctoral. Actualmente en prensa se encuentra la obra de Thomas Pink sobre la acción moral en Suárez, que esperamos pueda contribuir a la comprensión de la doctrina del granadino sobre el actuar moral ${ }^{7}$.

Si atendemos al itinerario académico de Suárez verificamos que siguió estudios jurídicos en Salamanca entre 1561 y 1564, continuando después, una vez ingresó en la Compañía de Jesús como parte de la tercera generación de jesuitas, el programa formativo establecido por esta orden entre los años 1564 y

Century Philosophy, Routledge, New York and London, 2017; Salas, V. M. \& Fastigi, R. L., A Companion to Francisco Suárez, Brill, Leiden-Boston, 2014; Novák, Lukáš (ed.), Suárez's Metaphysics in its Historical and Systematic Context, De Gruyter, Berlín, 2014; Hill, B. \& Lagerlund, H. (eds.), The Philosophy...ob. cit.; Scarbi, M. (ed.), Francisco Suárez and his legacy. The impact of suarezian metaphysics and epistemology on modern philosophy, Vita e Pensiero, Milano, 2010. Rhuterford, D. (ed). The Cambridge Companion to Early Modern Philosophy. CUP, Cambridge, 2007.

3 Vid. Penner, S., «Free and Rational: Suárez on the Will», Archiv für Geschichte der Philosophie, Vol. 95, 1, 2013, pp. 1-35.

4 Terence Irwing dedica, por ejemplo, dos capítulos a Suárez en su historia de la ética centrándose en estos aspectos: Cfr. IRwin, T., «Suárez: Law and Obligation», The Development of Ethics. Oxford University Press, Oxford, 2008, Tomo II («From Suarez to Rousseau»), pp. 1-27; Ibid. «Suárez: Naturalism», pp. 28-69;

5 Vid. Sydney Penner: Suárez in English Translation: http://www.sydneypenner.ca/ SuarTr.shtml (Accedido 21/07/2017)

6 Åkerlund, E., Nisi temere agat. Francisco Suárez on Final Causes and Final Causation. Edita Västra Aros, Västerås 2011. La obra consiste en un estudio monográfico detallado sobre la cuestión de la causalidad final en la Disputación XIX de la magna obra metafísica de Suárez.

7 Vid. Pink, T. L., «Agents, Objects and Their Powers in Suarez and Hobbes», Philosophical Accounts of Action from Suarez to Davidson, SANDIs, C. (ed.), Oxford, Oxford University Press, 2017. Thomas Pink publicó estudios importantes sobre la confluencia de tradiciones filosóficas en el siglo XVII, sobre todo en los dominios de la ética y de la filosofía del derecho. Para la cuestión que nos ocupa en este artículo dos de sus trabajos son particularmente esclarecedores: PINK, T., "Suarez, Hobbes and the scholastic tradition in action theory», in PInK, T; Stone, M. W. F. (eds). The Will and Human Action. From antiquity to the present day, Routdledge, London-New York, 2004, pp. 127-144, en las que analiza detalladamente la doctrina de Suárez sobre el acto voluntario, contrastándola con las de Aquino y Escoto. 
1570. En lo que se refiere a su metodología de trabajo y a las escuelas filosóficas a las que más se acerca, escribe Poncela:

«Formalmente, Suárez hereda de los maestros salmantinos la necesidad de acudir a las fuentes textuales, aunque estas fueran de procedencia diversa a la cristiana. Asimismo, adquiere el hábito de recorrer la vía nominalista y la escotista, concebidas como instrumentos indispensables para la clarificación del paradigma realista vigente, y, dentro de los estrechos límites que la época imponía al pensamiento, la forja de un criterio independiente, señal de identidad de los maestros salmantinos. Desde esta orientación, cobra sentido la crítica de Suárez al tomismo; ésta, no fue el resultado de una patología, como parecen suponer los críticos afines al angélico, sino una tendencia común y extendida en las aulas de la facultad de Teología de Salamanca» ${ }^{8}$.

Es a partir de este enfoque metodológico que Francisco Suárez inicia su labor como lector de Filosofía en Segovia (1571-1575), con apenas veinticinco años ${ }^{9}$. Subsisten algunos comentarios de esta primera época de su vida en la cual comentó la obra de Aristóteles, como estaba previsto en el plan de estudios de filosofía de los colegios jesuitas ${ }^{10}$. En la época inmediatamente posterior a esta, Suárez enseña teología en Valladolid (1576-1580). A este período se han atribuido sus primeros comentarios a la I-IIae de la Suma de Teología de Tomás de Aquino, de los cuales subsiste bajo forma manuscrita el tratado De beatitudine (qq. 1-5). El manuscrito fue descubierto por el P. Juan R. Lozano en 1945, en el colegio jesuita de Villagarcía ${ }^{11}$ y trasladado más tarde a la biblioteca del

8 Poncela González, Á., «Francisco Suárez», La Escuela de Salamanca: Filosofía y Humanismo ante el mundo moderno, Verbum, Madrid, 2015, p. 271.

9 Mantiene Elorduy que será precisamente en Segovia donde se formulen las primeras acusaciones a Suárez por enseñar una ética «cristiana sobrenatural distinguiendo el esse naturae del esse moris con tendencias anti-aristotélicas». ElorduY, E., «Datos para el proceso de beatificación del P. Francisco Suárez, S.I.», Archivo Teológico Granadino, n. ${ }^{\circ} 33,1970$, p. 133. Suárez se defenderá de estas acusaciones asegurando que no tiene intención de encontrar nuevas verdades, aunque sí de expresarlas de otro modo. Cf. Scoraille, R., El P. Francisco Suárez de la Compañía de Jesús según sus cartas, sus demás escritos inéditos y crecido número de documentos nuevos, trad. de P. Hernández, t. 1, Barcelona: Subirana, 1917, p. 156. Citado por Poncela González, Á., 2015. Ob. Cit. p. 276.

10 Entre ellos, el más conocido y estudiado es el comentario al De anima, aunque el itinerario de composición de la versión que hoy conocemos sea bastante complejo, como explica Castellote en la Introducción a su edición en castellano (1978). El mismo Castellote refiere que «La existencia de estos tratados filosóficos ha sido atestiguada por el mismo Suárez, quien en su tratado De anima, cita en varias ocasiones los siguientes: Peri Hermeneias, Libri Posteriorum, Libri Physicorum, Libri Praedicamentorum, De Caelo, De generatione et corruptione, y, posiblemente una Metafísica». CASTELlote, S., «Introducción», en Commentaria una cum quaestionibus in libros Aristotelis De anima. Introducción y edición crítica Salvador Castellote, vol. I, III vols. Labor, Madrid, 1978, pp. XXXVIII. Para el listado completo de los comentários filosóficos de Suárez subsistentes, sea en manuscritos, o impresos, vid. LoHR, C., Latin Aristotle Commentaries, Vol. II, Leo S. Olschki, Firenze, 1988, pp. 441-445.

11 Elorduy, E., "Suárez en la historia de la moral», Cuadernos salmantinos de filosofía, VII, 1980, pp. 133-147. 
seminario de Valladolid, donde se encuentra actualmente ${ }^{12}$. Suárez proseguirá comentando la Suma de Teología de Aquino en los años de Roma (1580-1585) y, como refiere Castellote, trabajará en estos comentarios hasta finales de su vida, como prueba su empeño en la preparación de un «fundamental estudio psicológico que pudiera servir de base filosófica a su teología como ya lo habían sido sus Disputaciones ${ }^{13}$. Tras su muerte, fue encomendada la edición de toda la obra aún inédita al jesuita Baltasar Álvares. Entre estas obras se encontraba el Comentario a la I-IIae de la Suma de Teología de Aquino, dividido en cinco tratados, cuya editio prínceps vería la luz en Lyon en $1628^{14}$, incorporándose ya en el siglo XIX en el volumen IV de la edición completa de las obras de Suárez publicada por Vivès en Paris ${ }^{15}$.

Para una mejor comprensión tanto del contexto histórico y doctrinal en el cual Suárez desarrolla sus tesis sobre el actuar humano y la naturaleza misma del hombre, como del contenido mismo e impacto de estas tesis en la posteridad, es importante conocer sus comentarios a la I-IIae de la Suma de Teología de Aquino. En este artículo nos proponemos traer a la luz algunos aspectos de la teoría suareciana sobre la causalidad del fin en el actuar humano, confrontando dos textos de distintos período que comentan la referida parte de la Suma: el comentario conservado en el manuscrito inédito De beatitudine (MDB) y el primer de los cinco tratados, intitulado De ultimo fine hominis, publicado por Baltasar Álvares ${ }^{16}$.

12 Francisco SuÁREZ, De beatitudine. Reproducimos la información de la ficha catalográfica realizada por Jacob Schmutz, en febrero de 2013, en la Biblioteca del Seminario de Valladolid: "Ms. Sin lugar, s. XVI ex.-s. XVII in. Contiene: 1. Expositio et questiones in quinque priores $I^{a e}-I I^{a e} D$. Thomae Aquinatis quaestiones materiam de beatitudine continentes, 208 p. Procedencia: recopilación de un curso de Francisco Suárez. Perteneció a la Librería del Colegio de Villagarcía. Olim: 1- 1- 7».

13 A este propósito, transcribe parte de una carta de Suárez en la que este manifiesta el deseo de revisar y terminar su obra filosófica, de tal modo que ésta se conforme con su teología: «Me veo ya muy avanzado en años para terminar los trabajos que tengo comenzados, y para poder dejar terminada una filosofía que corresponda a mi teología». Tomado de carta autógrafa de 10 de enero de 1617, dirigida al P. Vitelleschi, General de la Compañía de Jesús. Citado por Castellote (1978) Ob. Cit, p. IL.

14 EXIMII DOCTORIS P. FRANCISCI SUAREZ GRANATENSIS É SOCIETATE IESU IN ACADEMIA CONIMBRICENSI PRIMARII ATQUE EMERITII OILM PROFESSORIS, Ad primam secundae D. Thomae tractatus quinque Theologici, Quorum I. De ultimo fine hominis, ac Beatitudine. II. De voluntario, \& involuntario. III. De humanorum actuum bonitate \& malitia. IV. De passionibus \& habitus. V. De vitiis, atque peccatis. Lugduni, Sumptibus Iacobi Cardon, 1628. Esta misma obra vio su $2^{\text {a }}$ edición al muy poco tiempo: MoguntiaE, Editor sumptibus Hermanii Mylii Birckmanni, 1629.

15 Francisco SuÁrez, Opera Omnia, editio nova de André, D. M., París, Vivès, 1856-1866, edición en 24 volúmenes y dos de índices $(25-26,1878)$. El tratado De ultimo fine hominis está publicado en el volumen IV, 1861, pp. 1-156.

16 Las traducciones aquí presentadas son responsabilidad de las autoras. Las del Ms. De beatitudine (en adelante MDB, $\mathrm{n}^{\circ}$ de folio) están realizadas a partir del texto latino transcrito por Juan Antonio Senent y Andrés Oyola, en el ámbito del proyecto referenciado en nota 1, dentro del trabajo de traducción al castellano de ese mismo texto para una futura edición 
El análisis que aquí realizamos se asume como un instrumento heurístico cuyo objetivo es delinear la respuesta de Suárez a la cuestión sobre la causalidad del fin en los actos humanos tal como la presenta en el comentario del manuscrito de 1579 y en el comentario editado en 1628. A partir del dato historiográfico de las acusaciones de anti-aristotelismo, y por ende de antitomismo, recogidas por Elorduy, se pretende rastrear la posición de Suárez sobre aquella cuestión filosófica en los dos textos supra mencionados, cuya redacción dista más de treinta años ${ }^{17}$. Para ello se analizará la misma cuestión en ambas obras, verificando si la posición de Suárez ante la doctrina tomista puede o no justificar las referidas acusaciones.

\section{2. ¿Qué SIGNIFICA ACTUAR POR Un FIN? LA EXPLICACIÓN DE SuÁreZ EN El COMENTARIO DEL MS. DE BEATITUDINE (1579)}

Analizamos en primer lugar la respuesta a la cuestión tal como la explica Suárez en el comentario preservado en el ms. De beatitudine. Como es sabido, desde los tiempos de Francisco Vitoria se determinó que la enseñanza de teología en las universidades de la Península Ibérica seguiría como texto base de comentario la Suma de Teología de Tomás de Aquino ${ }^{18}$. Esta metodología se adoptará también en los colegios jesuitas y eso mismo se comprueba en el comentario de Suárez a la I-IIae, preservado en el MDB, en el que expone la cuestión sobre el fin último del hombre comentando la Suma de Teología de Tomás de Aquino Ia-IIa, cuestiones 1 a 5. Aunque no se trate de una paráfrasis, la exposición de Suárez sigue de cerca el texto de Aquino, organizándose mediante cinco cuestiones, con artículos en número variable que se corresponden con los ocho artículos en los que se divide cada una de las cuestiones de la Suma supra mencionadas. Igualmente, los títulos de las cuestiones coinciden con los del texto de Aquino, si bien en éste los artículos están enunciados como preguntas que se plantean como partes de la cuestión y que se considera necesario resolver para explicar la cuestión general. En el texto de Aquino, las respuestas se organizan sistemáticamente según el modo canónico que tiene el Doctor Angélico de aplicar la metodología de la quaestio ejercitada en las universidades medievales.

trilingüe. Para el comentario del 1628 utilizamos la edición latina referenciada en n. 16 . Las referencias a la Suma de Teología de Tomás de Aquino siguen la edición dirigida por los regentes de las provincias dominicas de España, 5 vols, Madrid, BAC, II', 1993, pp. 37-89.

17 Una vez que el comentario del MDB está fechado del 1579 y que, en la dedicatoria ad lectorem con la que abre la edición del De ultimo fine hominis (vid. n. 48), Baltasar Álvares dice que Suárez no daba a imprenta sus textos sin revisarlos, la fecha límite posible de composición de este tratado por Suárez se establece en 1617, año de su muerte.

18 Sobre la progresiva sustitución del comentario a las Sentencias de Pedro Lombardo por el de la Suma de Teología de Aouino en la enseñanza de Teología en la Universidad de Salamanca, y sobre la influencia de Francisco Vitoria en este cambio, vid. AnXo PeÑa, M., La Escuela de Salamanca, B.A.C., Madrid, 2009, pp. 28-33. 
En su comentario, en una exposición articulada de forma variable y a veces bastante extensa, Suárez presenta las cuestiones que había propuesto Tomás y analiza la interpretación que de ellas hace el doctor medieval. Suárez incorpora a su exposición de la doctrina de Aquino las principales teorías de los autores del siglo XIV y del XV sobre los mismos temas, sobre todo los que provienen de otras familias filosóficas, como es el caso de Duns Escoto y Gabriel Biel; añade igualmente Suárez las opiniones de los autores cuya interpretación se consagrara como canónica ad mentem Aquinatis, como es el caso de Cayetano. Este hecho hace que los argumentos explicados por Aquino sean ahora, en Suárez y en la generalidad de los comentadores escolásticos de los siglos XV y XVI, desplegados en múltiples sub-argumentos, bajo forma de un debate más amplio que cae dentro de las cuestiones de la Suma de Teología como su lugar formal, pero que en cuanto a su contenido material las trasciende en mucho ${ }^{19}$. El comentario de Suárez resulta, por consiguiente, en un texto mucho más extenso que el de Tomás que se propone comentar y revela la complejidad de los asuntos discutidos originada por el trascurrir de los tiempos y por los nuevos problemas a los que hay que contestar ${ }^{20}$.

Aunque las soluciones que aporta en su comentario de 1579 se puedan ubicar dentro de la escuela tomista, en no pocas ocasiones Suárez parece dudar sobre cuál sea la buena interpretación ${ }^{21}$. De este modo, deja antever la falta de uniformidad entre los teólogos sobre la doctrina de Tomás y que esta no es cierta ni incontestable para el mismo Suárez. Se presta especial atención aquí a estas vacilaciones manifiestas por Suárez sobre la interpretación de aquello que propiamente quisiera decir Tomás. Con ello se pretende identificar alguna posición que pudiera dar razón de aquellas primeras acusaciones de anti-aristotelismo y anti-tomismo recibidas por Suárez ya en Segovia, y que persistirían en el período de la enseñanza en Valladolid, que antes mencionamos. Para hacer manejable este objetivo se analizará sólo la cuestión primera

19 Este método es práctica corriente que fácilmente se comprueba cuando leemos manuscritos que contienen textos de los profesores de filosofía y teología de este período. Es frecuente que la cuestión y artículo de Tomás se despliegue, en el comentario, en «disputaciones», que versan sobre problemas específicos de interpretación o discusiones de escuelas sobre una cuestión determinada. Se trata de una metodología que conjuga el método dialectico, de la disputatio, con el de la quaestio, verificándose este ya insuficiente para contener el estado del debate. En el caso de Suárez, como se sabe, en escritos posteriores adoptará sistemáticamente el modelo de la disputatio, del que es ejemplo su magna obra de metafísica.

20 Mientras en la edición de la Suma de Teologia que manejamos, las cinco cuestiones apenas ocupan 52 páginas (pp. 37-89), de las cuales sólo 9 atienden a la primera cuestión (pp. 37-46); en la versión transcrita y traducida ad usum privatum que manejamos, v. nota 17, las cinco cuestiones se desarrollan a lo largo de 336 páginas, de las que 83 se refieren al comentario de la primera cuestión. La transcripción del manuscrito se extiende en 323 páginas, en formato pdf, no impresas.

21 Suárez intenta defender de algunos críticos la posición tomista, pero lo hace de modo no asertivo, presentando alternativas a la interpretación bajo forma condicional: «tal vez Tomás quisiera decir...». Cfr. Por ejemplo, MDB 9; En otras ocasiones critica directamente a Tomás Cfr. MDB 18. 
—sobre el fin último del hombre- de las cinco de las que se ocupa Suárez en los tratados De beatitudine, título por el cual se designaron los comentarios a la Suma de Teología, Ia-IIa qq. 1-5 entre los autores de la escolástica tardía.

Ambos autores, Aquino y Suárez, exponen su doctrina sobre el fin último del hombre como parte de la enseñanza de la ciencia teológica. Igualmente, uno y otro - y de modo más patente aún en el caso de Suárez- dejan claro que el discurso sobre la bienaventuranza supone conocer lo que es el hombre, muy en particular el modo de obrar de sus potencias propias que son las de conocer y querer. Suárez sigue a Tomás en la búsqueda de la fundamentación filosófica para la cuestión sobre la orientación del hombre a un fin último, interrogando ante todo si es propio del hombre actuar por un fin. Se trata de un planteamiento de principio: en tanto el objeto general del tratado es De beatitudine, esto es, el camino y la razón por la que el hombre tiene Dios como su fin último y objeto de su felicidad, la teología moral necesita saber qué caracteriza al hombre, en tanto humano, que permite distinguirlo de las demás criaturas. Como indica Suárez en el Proemio de este comentario se trata, en primer lugar, «del hombre en cuanto es agente libre y por medio de sus acciones alcanza o pierde la felicidad última, y todas las otras cosas que se consideran en esta parte y que se ordenan a dar a conocer al hombre, en cuanto que actúa libremente»22.

Por razones heurísticas y de método, se analiza aquí solamente el artículo primero de la primera cuestión, que interroga «si es proprio del hombre actuar por un fin» ${ }^{23}$. Una vez que para explicar esta cuestión Suárez indaga sobre lo que sea actuar por un fin apoyándose en categorías filosóficas de matriz aristotélica-tomista, pretendemos una aproximación a su filosofía moral, antes que a su teología ${ }^{24}$. A su vez, esta filosofía práctica se asienta en una psicología filosófica que pueda explicar el actuar de todo viviente, a fin de verificar en qué se distingue su modo de obrar de aquel propio del hombre. Finalmente, este conocimiento permite diferenciar el actuar humano libre del modo de actuar de otros agentes libres, como sean las criaturas superiores y el ente supremo ${ }^{25}$.

22 MDB 2: «Agitur enim in hac parte de homine ut est agens liberum et per actiones suas consequitur vel amittit felicitatem ultimam et reliqua omnia, quae in hac parte considerantur, ordinantur ad manifestandum hominem ut libere operatur».

23 MDB 2: «Utrum homini conveniat agere propter finem».

$24 \quad$ La importancia de esta cuestión puede asimismo sustentarse en un trabajo reciente de Penner, ibid. 2013, sobre la libertad de la voluntad en Suárez, en él se reconoce que si bien los argumentos proceden de las Disputaciones Metafísicas, es preciso reconocer el origen de lo que se ha denominado una «psicología moral» inspirada siquiera temáticamente en las q1-5 de la I-IIae de Tomás, ob. cit. 2013, p.3, y que podría encontrarse, mantenemos aquí, en los comentarios realizados por Suárez, tanto en el MDB como en el tratado De fine ultimo hominis. Cfr. BurLando, G. «Configuración psicológica de la libertad humana en F. Suárez», Teología y Vida, Vol. XL, 1999, pp. 31-48.

25 De esta última cuestión, que permite comprender por qué razón Suárez disocia el actuar libre del actuar finaliter y, por lo tanto, a afirmar que Dios no actúa por un fin, no nos ocupamos en este artículo. 
Para determinar si el fin del hombre, en cuya posesión se perfeccionan sus potencias propias, es Dios y cómo alcanzarlo, es necesario, ante todo, saber qué significa, en el caso específico del hombre, "actuar por un fin». Tomás había explicado el actuar humano a partir de Aristóteles y del movimiento de los agentes naturales en la Física y en el De anima. O sea, el modelo de Tomás está retirado de la filosofía natural aristotélica, pues explica el actuar humano ante todo como un modo de movimiento que se verifica en las sustancias corpóreas. Una vez que el hombre es uno más entre éstas, su actuar se explicaría igualmente como un tipo de tránsito causado por la afección de actos en potencias proporcionadas, ya que esta es la estructura fundamental de todo movimiento u operación.

De Aristóteles Tomás había igualmente asumido el principio de causalidad final universal, según el cual todo el agente actúa en vista de un fin, cabiendo solamente distinguir modos de perseguir la finalidad según los distintos modos de ser. Así, hay un modo de perseguir el fin que es propio de la naturaleza no animada. Esta, al no estar dotada de cualquiera capacidad de relacionarse cognitivamente con el entorno, alcanza su fin indirectamente, por acción de un principio extrínseco inteligente que, en última instancia, es la inteligencia suprema creadora. Lo mismo ocurre con los seres vivos irracionales. También ellos al actuar buscan un fin: la preservación de su vida o de la especie. Sin embargo, tampoco ellos conocen el fin que persiguen, sino que se dirigen a cada uno de los bienes particulares que les mueven a actuar por la conveniencia y proporción que tienen con sus potencias sensitivas. Finalmente, están las criaturas racionales entre las cuales se encuentra el hombre. Estas buscan el fin orientando hacia él sus propios actos, con conocimiento y voluntad deliberada.

En el MDB Suarez retoma esta explicación aristotélica-tomista de la causalidad final universal ${ }^{26}$, explicando que, con esta distinción entre grados de ser y modos de alcanzar el fin, Tomás parece haber querido avanzar más allá de lo que estaba evidente en el título de la pregunta. Pues al ser evidente «que el hombre actúa por un fin, no quiso discutir solamente lo que era evidente, sino más bien definir alguna otra cosa que podría parecer más oscura; y principalmente quiso presentar la propia razón por la cual el hombre posee el actuar por un fin $»^{27}$.

Si, como piensa Suárez, la explicación de Tomás pretende esclarecer en qué sentido se dice que es propio del hombre actuar por un fin; y si el hombre, en la medida en que es un viviente, realiza acciones que también realizan los

26 Esta distinción entre el modo de natural de actuar por un fin y el modo racional se encuentra en Tomás DE Aouino, S. Th., I-II q. 1, a. 1, resp., que es el texto que Suárez comenta.

27 MDB 3: «(...) in conclusione [Thomas] plus videtur respondere quam in titulo quaesierit, nam quaerit indefinite an homo operetur propter finem et respondet distributive hominem in omni operatione humana operari propter finem nam, cum per se notum sit hominem operari propter finem, noluit disputare tantum id quod per se notum erat sed definire aliquid aliud quod obscurius videri poterat et praecipue voluit reddere rationem propriam propter quam homo habeat operari propter finem». 
seres animados inferiores, para entender la doctrina de Tomás, dice Suárez, es necesario «explicar las acciones que el hombre posee como propias suyas, en cuanto que es hombre, y aquellas que se dicen propiamente humanas en Teología moral; y así se tornará evidente de qué modo y en cuáles de ellas el hombre actúa por un fin ${ }^{28}$.

La dificultad de la cuestión deriva de la propia estructura del ente humano, en el que se encuentran potencias naturales y potencias libres. Y una vez que «hay muchas acciones humanas en las que el hombre no se mueve libremente, sino que actúa naturalmente ${ }^{29}$, importa saber si en todas ellas el hombre actúa por un fin y, en caso afirmativo, comprender hasta qué punto su actuar es natural y necesario, o libre y responsable. En último término, el problema con el que aquí se debate Suarez es el de identificar dónde pasa la diferencia entre el actuar natural y el libre, y cuál es la especificidad de éste último. Identificada esta, se encontrará la correcta definición de lo que es el hombre, se podrá establecer la frontera entre mundo natural y mundo moral y orientar correctamente el actuar hacia el fin último.

Apoyándose en el De anima de Aristóteles, obra que había comentado pocos años antes en los cursos de filosofía ministrados en Segovia, Suárez describe el modo como comprende la relación, en la substancia que es el hombre, entre naturaleza y racionalidad/libertad. En el hombre, dice, «se encuentran diversas y múltiples acciones de todos los grados». Sin embargo, «se debe de hablar de las vitales pues solo estas merecen el nombre de acciones» ${ }^{30}$. Ahora bien, ¿en qué consiste una acción vital? En que procede «de un principio intrínseco y, en los que son capaces de sentir, del alma que les informa» ${ }^{31}$. En el caso del hombre, el alma que le informa y le hace capaz de sentir es un alma racional: todo su actuar se encuentra «informado» por ese principio superior.

«(...) y así toda acción vital sea según ella propia en su totalidad, sea según algún aspecto suyo, procede del alma racional como tal, y por tanto puede decirse acción propia del hombre en cuanto hombre, porque procede del

28 MDB 4: «Ad intelligendam doctrinam divi Thomae explicandum est quas operationes habeat homo sibi proprias ut homo est et quae earum dicantur proprie humanae in Theologia morali et inde constabit quo modo et in quibus earum homo propter finem operetur».

${ }^{29}$ MDB 3: «(...) utrum homo in omni operatione humana et in illa sola operetur propter finem videtur quod non, primo quia sunt multae operationes humanae in quibus homo non se movet libere sed naturaliter agitur (...)».

30 MDB 4: «(...) in homine varias et multiplices graduum omnium operationes reperiri, loquendo, tamen, de vitalibus quae solum mereantur nomen operationum». Itálico nuestro. Esta es una convicción que Suárez siempre defenderá y que se encuentra, por ejemplo, en los tratados publicados en 1628 De voluntario et involuntario y De passionibus. Sobre las consecuencias de esta tesis en la psicología filosófica de Suárez, vid. Oliveira E Silva, P., «Elementos de psicología metafísica no De passionibus de Francisco Suárez», in Francisco SuÁrez. As Paixões...ob. cit., pp. 15-23.

31 MDB 4: «(...) procedit, enim, actio vitalis a principio intrinseco et in sensibilibus ab anima informante». 
principio constitutivo del hombre en cuanto tal; y lo mismo es evidente inductivamente en todas sus acciones» ${ }^{32}$.

Suárez defiende, por lo tanto, en el hombre la unidad substancial entre cuerpo viviente y alma racional. Esta última, informando toda su vida sensitiva, eleva las acciones vitales a un modo de vida de grado superior que es proprio de la naturaleza humana. Por eso es posible afirmar que todas las acciones del hombre, aun las naturales y necesarias, son acciones humanas. Estas acciones propias del hombre, "que son connaturales y conformes a la naturaleza humana, todas conducen de algún modo a alcanzar el fin del hombre, porque la naturaleza nada hace en vano o sin orden $»^{33}$. Si es así, ese actuar natural del hombre tiene que ordenarse al actuar libre que le es propio, como explica Suárez:

«Además, porque el alma del hombre se une al cuerpo para hacer uso de él como de un instrumento para su perfección, de ahí se sigue por una parte, que todas las potencias se ordenan a alcanzar la perfección del alma y por otra eso mismo manifiesta la consonancia entre las dichas operaciones ${ }^{34}$.

32 MDB 4-5: «(...) et ita omnis actio vitalis vel secundum se totam vel secundum aliquid sui procedit ab anima rationali ut sic, et ideo potest dici propria ac[5]tio hominis ut homo, quia procedit a principio constitutivo hominis ut sic. Idemque patet inductive in omnibus eius operibus».

33 MDB 5: «(...) haec operationes propriae hominis, quae connaturales sunt et consentaneae naturae humanae omnes conducunt aliquo modo ad finem hominis consequendum, quia natura nihil facit frustra nec inordinate». Este es un adagio de inspiración estoica que encontramos frecuentemente citado en los comentarios filosóficos y teológicos de la época.

34 MDB 5: (...) quia anima hominis unitur corpori ut eo utatur tamquam instrumento ad suam perfectionem et ideo omnes potentiae ordinantur ad perfectionem animae consequendam et hoc ipsum ostendit consonantia dictarum operationum, nam opera potentiae vegetativae conducunt ad perfectam corporis dispositionem consequendam». Esta explicación sobre el modo como naturaleza y racionalidad se co-implican en el actuar humano no se encuentra en el texto de Tomás que Suárez comenta. A la vez que defiende la unidad substancial entre cuerpo natural y alma racional, Suárez no deja de tener en cuenta la especificidad de cada una de estas dimensiones humanas. Incluso, en este paso del MDB utiliza la metáfora de matriz platónica, dualista, del cuerpo instrumento del alma. Reconoce que el inferior se ordena al superior manifestando, la consonancia entre el cuerpo y las potencias vegetativas. A su vez esta armonía está ordenada «al perfecto uso de todas las potencias de los sentidos. Estas, sin embargo, están al servicio de las operaciones espirituales del alma, pues la cognición sensitiva se ordena a la cognición espiritual del intelecto. En cambio, las pasiones del apetito sensitivo se ordenan por naturaleza sea a la conservación del cuerpo, sea, especialmente en el hombre, al servicio de las acciones de la voluntad, pues con frecuencia disponen el hombre a realizar perfectamente los actos de virtud, a elegir correctamente, etc.» MDB 5: «Haec ordinatur ad perfectum usum omnium virium sensitivarum. Haec autem deserviunt operationibus spiritualibus animae, nam cognitio sensitiva ordinatur ad cognitionem spiritualem intellectus. Passiones, autem, appetitus sensitivi ex natura ordinantur et ad conservationem corporis et specialiter in homine ut deserviant actionibus voluntatis, nam saepe disponunt hominem ad perfecte operandum opera virtutis, recte eligendum, etc.» Todo ese actuar humano, simultáneamente natural y libre, conduce a la perfección del hombre y manifiesta estar direccionado a un fin último: «(...) las naturales o son el comienzo 
Si es así, aunque en el hombre todo su obrar sea humano, no todo se ejerce de modo propio y perfectamente humano. El actuar humano natural se puede considerar

«(...) de dos modos, primero según su sustancia y entidad, en cuanto que existen independientemente de la voluntad deliberada, y de este modo, aunque en entidad difieran de las acciones de los irracionales y de otras cosas naturales, sin embargo, no difieren en el modo como se realizan, porque solo se realizan de cierto modo natural y por una necesidad que procede de la inclinación natural; por ello, como tales no son dignas de premio o castigo, porque si hablamos solamente en este modo de actuar, el hombre más es movido que se mueve a sí mismo»»35.

Este modo de actuar natural del hombre es actuar humano y, como todo actuar, se dirige hacia un fin. Así lo entendiera Aristóteles y así explica Suárez que lo entendió Tomás: «sobre el texto de santo Tomás se debe tan solo advertir que él deduce la razón de fin en las obras de la naturaleza del hecho de que la naturaleza en sus acciones tiende a determinados efectos» ${ }^{36}$.

Sin embargo, estas acciones como tales

«no son propiamente medios por los cuales el hombre tiende a su fin, porque el hombre alcanza el fin último no solo a través de la perfección natural congénita de su naturaleza, sino principalmente a través de las buenas previas, y por tanto no lo alcanza a través de actos enteramente necesarios ${ }^{37}$.

y fundamento de las libres o son como que el último término de todo su camino. Y así es evidente que todas las acciones propias del hombre se dan de algún modo por el último fin». MDB 5: «Naturales vero vel sunt initium et fundamentum liberarum vel sunt quasi ultimus terminus totius huius viae. Et ita constat omnes operationes hominis proprias esse aliquo modo propter ultimum finem».

${ }_{35}$ MDB 5: «(...) has operationes dupliciter considerari posse, primo modo secundum substantiam suam et entitatem ut sunt independenter a voluntate deliberata et hoc modo, etsi in entitate differant ab actionibus brutorum et aliorum rerum naturalium, tamen, in modo quo fiunt non differunt, quia solum fiunt quodam naturali modo et necessitate procedente ex naturali inclinatione, unde ut sic non sunt dignae praemio aut poena, quia tantum loquendo in hoc modo operandi, magis movetur homo quam se move [6] (...)». Suárez fue sensible a la dimensión anímica y vital del hombre en la explicación cabal del actuar humano y en la determinación de la moralidad del acto al punto de escribir todo un tratado (el IV de los tratados morales) De actibus qui vocantur pasiones. Aunque estos actos procedan del principio vital que se manifiesta en la vida misma corpórea y natural del hombre, precisamente porque esta es asumida por el alma racional, es importante conocer el modo de interacción entre estas dos dimensiones, sensitiva y racional, para evaluar correctamente la calidad moral de los actos humanos.

36 MDB 15: «(...) circa litteram divi Thomae, solum notandum est illum colligere rationem finis in operibus naturae ex hoc quod natura in suis actionibus tendat ad determinatos effectus».

37 MDB 6: «(...) istae operationes ut sic non sunt proprie media, per quae homo tendit in suum finem, quia homo consequitur finem ultimum non solum per modum naturalis perfectionis congenitae naturae sed praecipue per modum praeviorum bonorum operum et ideo non consequitur illum per opera omnino necessaria». 
El comentario de Suárez prosigue para el art. 2 de la q. 1 de la Ia-IIa, en el que Tomás pregunta «si es proprio de la creatura racional actuar por un fin» y se inicia con una síntesis didáctica de las conclusiones de lo expuesto en el art. 1. Dice Suárez: «Los agentes naturales obran por un fin; sin embargo, lo hacen por una razón distinta que el hombre, pues este se mueve a sí mismo a un fin, pero aquellos más bien son movidos que se mueven a un fin ${ }^{38}$. Suarez explica que el objetivo de Tomás en el art. 1 de la q. 1, al analizar qué significa «actuar por un fin», es tríplice:

«(...) [i)] bien para explicar que el hombre posee algo propio en el actuar por un fin, [ii)] bien para mostrar que, aunque el hombre actúe por un fin a causa de la razón que posee, los demás agentes inferiores también no son totalmente excluidos del actuar por un fin, [iii)] bien, finalmente, para explicar de qué modo en las acciones naturales el hombre actúa por un fin» ${ }^{39}$.

Para el objetivo heurístico aquí propuesto y antes mencionado, se recogen tan solo los argumentos y doctrinas expuestos por Suárez sobre el punto i) qué es ese quid proprium que el hombre posee al actuar por un fin. Siguiendo a Tomás, afirma en primer lugar que «es cierto que el hombre actúa propia y perfectamente por un fin, moviéndose a sí mismo hacia él y eligiendo los medios en vista de él» ${ }^{40}$. Efectivamente, según Aristóteles y la interpretación que de él hace Tomás de Aquino, el actuar propiamente humano deriva de «la razón» o de la «voluntad deliberada», entendiendo por voluntad deliberada aquella informada por la razón. Es esta última la que conoce la razón de fin. Ahora bien, el quid proprium de la causalidad final en los agentes libres consiste exactamente en conocer la razón de fin. Suárez asume aquí esta misma doctrina al admitir que «la conclusión es evidente, por la razón natural, del mismo modo que los hombres son racionales y poseen libre arbitrio, pues a partir de lo que es racional se sigue que puede conocer propia y formalmente la razón de fin y la proporción de los medios con el fin ${ }^{41}$.

38 MDB 15: «Conclusio: agentia naturalia agunt propter finem, diversa tamen ratione quam homo, nam hic movet se in finem, illa vero potius aguntur quam se moveant in finem».

39 MDB 15: «Quaestio huius articuli physica est, tamen introducitur a divo Thoma tum ut explicet quid proprium habeat homo in operatione propter finem, tum ut ostendat quod, etsi homo operetur propter finem propter rationem quam habet, nihilominus alia agentia inferiora non excluduntur omnino ab operatione propter finem, tum denique ut explicet quomodo in operibus naturalibus homo operetur propter finem».

40 MDB 6: «Dico primo: certum est hominem operari propter finem proprie et perfecte sese movendo in illum et eligendo media ex intentione illius». El término latino intentio-nis es de difícil traducción, la cual debe ser contextualizada en las doctrinas de cada autor sobre el actuar natural y libre. Aquí optamos por la expresión «em vista de», pero se podría decir igualmente "por la fuerza de él [el fin]». O sea, es el fin el que ejerce presión sobre la potencia electiva para que actúe del modo que le es propio, a saber, eligiendo.

${ }_{41}$ MDB 7: «Ratione etiam naturali est evidens conclusio, sicut homines esse rationales et habere liberum arbitrium, nam ex eo quod rationalis est sequitur quod possit cognoscere proprie et formaliter rationem finis et proportionem mediorum cum fine». 
En conformidad con Tomás, Suárez adopta como características del actuar propiamente humano el hecho de que procede i) de la razón, que permite al hombre el conocimiento de la ratio finis y de la proporción y conveniencia de los medios para alcanzarlo y ii) de la voluntad que, movida por esta razón formal de fin inherente al bien conocido, delibera y orienta hacia él la acción humana, eligiendo el camino a seguir para alcanzarlo.

Si es así, se puede establecer que en los actos meramente naturales, al no haber conocimiento del hecho de que las cosas perseguidas son fines, el actuar del agente antecede el uso libre de la voluntad. Es lo que pasa en las acciones del hombre realizadas en estado de sueño o de inconsciencia. Inversamente, el actuar humano tiene como quid proprium «el dirigir sus acciones por medio de su razón y voluntad $»^{42}$. Luego solo obra libremente quien hace uso de la razón y de la voluntad antes de actuar. La causa y la orientación de la acción están ubicadas en la facultad de la razón y de la voluntad, a la cual Tomás llama de libre albedrío y que es el fundamento del actuar libre del hombre. Sin embargo, cabe preguntar legítimamente: ¿en qué consiste este poder? ¿Cuál es la causa propia del actuar libre? Siguiendo a Tomás, Suárez lo explica con llaneza: «Se llama voluntad deliberada la que actúa con pleno poder de la voluntad, con pleno conocimiento y juicio sobre lo que debe hacerse» ${ }^{43}$. Por medio de ella, el hombre es dueño y señor de todas sus acciones, también de las naturales, pues

«(...) este tipo de acciones como tal están al servicio del hombre como medios propios y adecuados por los cuales tiende a alcanzar su fin, porque en este modo de actuar específicamente se mueve a sí mismo hacia un fin y por razón de estas acciones es digno de alabanza o censura, de premio o culpa, porque actúa con suficiente conocimiento y poder de actuar o no actuar» ${ }^{44}$.

Esta es exactamente la ratio liberi arbitrii, que Tomás designa como «facultad de la voluntad y de la razón, porque tal poder está formalmente en la voluntad y radica en la razón, y por razón de esta facultad libre el hombre tiene dominio intrínseco de sus acciones (...)» $»^{45}$. Según esta doctrina, el libre arbitrio es dónde se ubica la libertad humana y el movimiento propio del hombre por un fin. Es esta una facultad que podríamos denominar simbiótica, pues recibe su forma de la voluntad, para que sea libre, pero radica en la razón, para que su actuar

42 MDB 7: «Sed hoc est proprium naturae rationalis dirigentis suas actiones per suam rationem et voluntatem".

43 MDB 6: Dicitur, autem, voluntas deliberata quae operatur cum plenaria potestate voluntatis cum plena advertentia et iudicio circa rem agendam».

44 MDB 6: «(...) et hujusmodi actiones ut sic deserviunt homini ut propia et consentanea media per quae tendit ad sui finis consecutionem, quia in isto modo operandi proprie sese movet in finem et ratione harum operationum est dignus laude vel vituperio, praemio aut poena, quia operatur cum sufficienti cognitione et potestate operandi vel non operandi».

45 MDB 6: «(...) in qua consistit ratio liberi arbitrii, quod a divo Thoma dicitur facultas voluntatis et rationis, quia illa potestas formaliter est in voluntate et radicatur in ratione et ratione huius liberae facultatis habet homo intrinsecum dominium suarum operationum, quod non consistit in hoc quod est possidere actionem, quia etiam possidet actiones mere naturales». 
sea plenamente consciente, derive del conocimiento de la ratio finis y resulte del juicio sobre la proporción entre medios y fines. En esto consiste la voluntad libre o deliberada, que, según Tomás, es el centro del actuar libre. Solo cuando obra por medio de esta facultad el hombre tiene dominio sobre sus propios actos. Y solo cuando actúa a partir de este pleno poder sobre sí mismo se puede decir que su actuar es plenamente humano o, lo que es sinónimo, sujeto a evaluación moral. De hecho, puede ocurrir que haya acciones humanas que procedan del conocimiento del fin y que no sean libres, ya que sobre ellas el hombre no ejerce pleno dominio. Y estas no pueden tener el mismo pondus moral que las que se hacen con pleno dominio de sí. Porque el hombre las domina, solo estas últimas pueden ser dirigidas y orientadas por él hacia un fin sin ningún tipo de coacción o constreñimiento ${ }^{46}$.

De este modo, el actuar libre se caracteriza por el dominio pleno del hombre sobre sus facultades superiores y no tanto por el hecho de ser movido por un fin. Esta es precisamente la tercera de las conclusiones que Suárez saca de esta doctrina: «todas las acciones que proceden de la plena advertencia de la razón con poder pleno o deliberación de la voluntad, están de algún modo relacionadas con el fin y [son] a causa del fin ${ }^{47}$. Sin embargo, si esto resulta de la argumentación anterior, es cierto la proposición contraria no es necesariamente verdadera.

¿Qué significa, por lo tanto, propia y perfectamente, actuar por un fin? ¿Es lo mismo que actuar libremente? Para Tomás, y Suárez con él, realmente no es así, dado que puede haber acciones libres que no se dirigen hacia un fin, como es el caso del actuar de Dios con relación a si mismo. En Dios, conocer y querer son su misma esencia y no hay tensión interior (intención) hasta un bien que sea otro de sí. Por otra parte, hay acciones no libres que son finalizadas, como es el caso de las que realizan los irracionales, los dementes y los niños, los tres casos de agentes típicamente asociados por los autores escolásticos al actuar no libre. Estos alcanzan su fin indirectamente, por medio de una racionalidad superior que no puede faltar en el universo, que orienta todo actuar a la finalidad que le es propia y proporcionada, dentro del orden cósmico.

Según Tomás, ser libre es ser capaz de conocer aquello que se presenta a la voluntad como un fin para el agente y moverse hacia él en razón de ese mismo

46 Podría objetarse aquí, que también aquellas acciones vitales guiadas por el instinto quedan orientadas, pues tienen una determinada finalidad natural, mantenerse con vida, por ejemplo; sin embargo, consideramos que la «dirección» a la que alude Suárez aquí es una dirección orientada por la razón de fin, una dirección racionalizada, intelectualizada si se quiere, de la que se sirve la voluntad para actuar. En las acciones vitales, respirar, por ejemplo, la voluntad no tiene capacidad de intervención porque, aunque conozca la razón de fin: en cuanto respira, no le es dado elegir entre respirar y no respirar. El actuar de las potencias vitales tiene una dirección única en la que no cabe alternativa. Por ello, no puede ser orientada libremente.

47 MDB 7: «(...) omnes operationes hominis quae procedunt ex plena advertencia rationis cum integra potestate seu deliberatione voluntatis sunt aliquo modo circa finem et propter finem». 
conocimiento. Actuar por un fin resulta por lo tanto de dos actos cognitivos: el conocimiento del objeto según su razón de fin para la voluntad y el juicio deliberativo sobre los medios para lograr ese fin. Así se distingue la causalidad del fin de los agentes naturales y libres, según Tomás: en el conocimiento de la razón de fin, que los primeros no poseen. Esta es en síntesis la doctrina explicada por Suárez en el comentario de 1579.

Como se vio, según Tomás es la potencia racional la que fundamenta el actuar por fines. En última instancia, es ella la que pone en movimiento el actuar humano por fines, la que determina, orienta y direcciona la voluntad humana. Sin embargo, esta deducción encierra alguna contradicción pues al ser así, el conocimiento de la razón de fin es causa necesaria de la elección, condicionando de algún modo a la voluntad. Como dice Suárez,

«(...) actuar por un fin no incluye formalmente la libertad, sino que supone el conocimiento de la razón en la cual el fin y el medio son formalmente conocidos; y se dice que la voluntad desea voluntariamente uno a causa del otro. Sin embargo, que lo desee libremente o no, en nada parece pertenecer a la causalidad del fin» ${ }^{48}$.

En el comentario del manuscrito de 1579, Suárez registra esta conclusión que deriva de la posición de Tomás, pero de cuya justeza no parece estar cabalmente convencido.

3. ¿Qué Significa «actuar por un fin»? La Respuesta de Suárez en el De ultimo FINE HOMINIS (1628)

Como antes se dijo, la obra de Suárez con el título latino De ultimo fine hominis contiene el comentario del teólogo granadino a la I-IIae de la Suma de Teología de Aquino en la edición póstuma organizada por Baltasar Álvares. Este, en las palabras iniciales que dedica ad lectorem, explica el método que siguió en la edición indicando expresamente que publica «(...) los comentarios que [Suárez] en otro tiempo había dado a sus alumnos por España, y no en un solo lugar, o en Roma» ${ }^{49}$. Si es así, el comentario de 1628 resulta de una compilación de los materiales escritos por Suárez y utilizados entre los años 1574-1580 para la enseñanza de teología impartida en distintas ciudades de España (Valladolid, Segovia, Ávila) y en los cuales siguió trabajando en los años romanos, o sea, entre 1580 y 1585 . Álvares informa que da a imprenta este material y asegura que Suárez los habrá revisado pues al ceder sus manuscritos

48 MDB 9: «Ratio est quia operari propter finem non includit formaliter libertatem sed supponit cognitionem rationis qua cognoscantur finis et medium formaliter et dicitur quod voluntas voluntarie appetat unum propter alium. Quod vero appetat libere vel non, nihil referre videtur ad causalitatem finis».

49 Álvares, B., "Ad lectorem» in F. Suarez, De ultimo fine hominis [Trac. I], Vivès, Paris, 1861: «Ergo quas eo de argumento, vel per Hispaniam, non uno in loco, vel Romae commentationes olim dederat (...)». 
a otros (como hubiera hecho con el propio Álvares) exigía revisarlos y validarlos antes de que fueran publicados:

«(...) si son un tanto desordenados no los desprecies o los subestimes, escritos como están por el mismo genio de Suárez. Algunos escritores de nota no han tenido pequeña parte en ellos apoyando el mismo tema que se publica. La sencillez de Suárez fue entonces, como lo ha sido siempre, tan grande, fue tan poco celoso de los que alguna vez le pedían sus trabajos, que nunca los negó a nadie, sólo con la condición que fueran supervisados por él para la imprenta ${ }^{50}$.

La organización temática de estos tratados morales sigue el orden del texto de Aquino que comentan ${ }^{51}$. Siguiendo el método de exposición utilizado por Suárez en sus tratados filosóficos y teológicos de madurez, el tratado De ultimo fine, que comenta a la I-IIae qq. 1-5, se divide en disputaciones ${ }^{52}$. Por lo tanto, en su organización interna diverge de la exposición del mismo Aquino y del comentario manuscrito de 1579. Lo que aquí pretendemos verificar es si se comprueban igualmente divergencias en cuanto al contenido doctrinal.

Analizando el texto del comentario de 1628 se verifica que la respuesta de Suárez a la cuestión de la causalidad del fin en la determinación de los actos humanos es efectivamente distinta de la explicada en 1579. Como se dijo, en el comentario conservado en el MDB hay dos características importantes en

50 Ibid.: «(...) si laciniosas minus, minime certe degeneres, minime enerves, ab ipso videlicet Soarii Marte progenitas. In quibus plane nobiles aliquot scriptores non parum praesidii in ejusdem argumenti opere vulgando habuere. Tantus scilicet erat tunc, ac fuit semper, Soarii candor, tam minime invidebat unquam poscentibus labores suos, ut nulli penitus eos denegaverit, illo titulo, quod essent a se praelo subjiciendi». No es fácil saber hasta qué punto dar crédito a estas palabras de Álvares ya que pueden corresponder a una captatio benevolentiae. El único modo de confirmar la autoría de estos tratados es confrontar el texto con el manuscrito original. Según Zulueta, A., «Manuscritos portugueses de Suárez» in Revista Portuguesa de Filosofia $\mathrm{n}^{\circ}$ 3, fasc. 4 (1947) 391, el ms. utilizado en la edición Vivès 1878 para el tratado De ultimo fine estaría en la Biblioteca Nacional de Portugal (BNP) con la signatura FG 2810. Sin embargo, en la investigación que realizamos no nos fue posible localizar este códice. Por otra parte, la información dada por Zulueta es contradictoria pues en la parte final del artículo da por perdidos los manuscritos de los tratados morales publicados por Álvares (cf. Ibid., p. 398). F. Stegmüller refiere la existencia, sea en la BNP, sea en la Biblioteca Geral da Universidade de Coimbra, de algunos mss. conteniendo comentarios a la I-IIae de Aquino (Cfr. Stegmüller, F., Filosofia e Teologia nas Universidades Portuguesas de Coimbra e Évora no séc. XVI, Universidade de Coimbra, Coimbra, 1959, p. 15). Una vez que es frecuente verificar imprecisiones en las informaciones dadas sobre estos códices, es de suma importancia verificar, en los respectivos acervos, los datos compilados en la literatura.

${ }^{51}$ Como antes se recordó, Tomás sigue el método escolástico practicado en las universidades medievales, dividiendo el objeto de estudio en cuestiones y subdividiendo estas en artículos. El comentario de Suárez a la I-IIae de la Suma de Teologia se divide en 5 apartados, como sigue: 1 - sobre el último fin del hombre; 2 - el voluntario y el involuntario; 3 - la bondad y malicia de los actos humanos; 4. De los actos que se llaman pasiones; 5 Sobre los pecados y vicios.

52 Vid. n. 21. 
la explicación de Suárez sobre la causalidad final. En primer lugar, persigue la demostración de la afirmación aristotélica-tomista sobre la causalidad universal del fin y para ello explica de qué modo naturaleza y libertad son afectadas por este actuar. Substantialiter, es decir, en cuanto cosas que forman parte del mundo creado, todo agente actúa por un fin. En segundo lugar, una vez que no todos agentes buscan el fin del mismo modo, se hace necesario identificar el modo humano de dirigirse a un fin. Ese modo es el actuar libre, o sea, realizado por medio de la simbiótica facultad de la voluntad y de la razón que es el libre arbitrio. Sin embargo, cuando se trata de definir exactamente en qué consiste el «actuar libremente por un fin», la doctrina de Tomás parece presentar a Suárez algunas perplejidades, casi como si le fuera difícil suponer que él pudiera decir que ser libre es ser racional, identificando la causalidad del fin con la acción que el fin ejerce sobre el intelecto.

Tal como había hecho en 1579, también en el comentario de 1628, luego en el Proemio, Suárez declara que, aunque su exposición sobre el fin sea teológica, pues incide sobre el último fin en cuya pose descansa el deseo humano de felicidad, la explicación de esta doctrina está soportada, como en su condición de posibilidad, por el conocimiento filosófico de lo que es el hombre y este conocimiento es la materia próxima de la teología moral ${ }^{53}$. Más aún, el hecho de que el hombre actúa libremente y tiende a la felicidad no necesita siquiera demostración: es un hecho evidente, de experiencia común, que cada uno comprueba en el ejercicio mismo del actuar humano ${ }^{54}$. Es cierto, prosigue Suárez, que la suya es una filosofía que explica la realidad humana a la luz y en función de un fin último trascendente y por eso mismo, este saber filosófico tiene Dios como su objeto. Y así, aunque al estudiar el hombre en cuanto se dirige a un fin último, no examine a Dios de modo directo, como lo hace la teología fundamental, se trata realmente de teología, pues Dios es aquí estudiado en cuanto último fin ${ }^{55}$.

Aquí analizamos principalmente los argumentos sobre el modo como el fin mueve causalmente la voluntad expuestos por Suárez en la Tratado I, Disputación I, secciones I e II. Esta exposición, dice Suárez, tiene por objeto analizar la bondad y malicia de las acciones humanas, pues es esta la distinción

53 Ibid., 2, p. XIV: «(...) ad doctrinam autem moralem maxime fuit necessaria homini cognitio sui ipsius, et actionum suarum, non autem aliarum creaturarum, nisi quatenus huic morali doctrinae deservire potest».

54 Cfr. Suárez, F., Tract. I, Prooemium, 1, p. XIII.

55 Ibid., 2; 8, pp. XIII.XIV. Esta observación, metodológica pero con alcance doctrinal, es importante para las conclusiones que presentaremos en epígrafe. Suárez asume explícitamente que la suya es una explicación filosófica sobre la causalidad del fin, aunque ésta se desarrolle en el ámbito de una teología moral, pues analiza el hombre en su movimiento de regreso a Dios. Sobre el modo como Suárez entiende las relaciones entre filosofía y teología vid. Esposito, C., "Suárez and the Baroque Matrix of Modern Thought» en SALaS, V.; Fastiggi, R. (eds), A Companion to Francisco Suárez, Brill, Leiden-Boston, spec. pp. 124-131. Aunque Esposito analice en particular esta relación a partir de las Disputaciones Metaphysicae, la misma matrix se verifica para la relación entre filosofía práctica y teología moral. 
decisiva para que el hombre pueda alcanzar Dios, como su fin último. A su vez, esta frontera es posible solamente cuando se pueda contestar a esta pregunta fundamental: ¿En qué consiste propia y perfectamente el actuar humano? La respuesta de Suárez es llana: en actuar por un fin.

Esto ya lo había argumentado en el comentario de 1579. Sin embargo, allí caracterizaba el actuar humano por su racionalidad, en la medida en que es el intelecto el que conoce la ratio finis. Por contraste, en el comentario publicado en 1628, la doctrina de Suárez sobre el locus finis en el actuar humano es anunciada desde el primer momento: «Ante todo hay que dejar establecido que el fin y su causalidad, cualquiera que ellos sean, tienen su propio lugar en la voluntad humana y en sus acciones o efectos (...) $\aleph^{56}$. Es cierto que la decisión humana no es ajena a la acción del intelecto, pues el conocimiento del fin es condición necesaria al ejercicio de la libertad. Sin embargo, tal conocimiento no es condición suficiente del actuar humano, pues alguien podría conocer el fin y no moverse en dirección a él. Eso significa que no es el intelecto la sede del actuar libre. Este último, defiende ahora Suárez, consiste en un movimiento intrínseco de la voluntad hacia el fin, por sí misma y desde sí misma. Por otra parte, es el fin en cuanto tal, y no su conocimiento por la razón humana, que pone en marcha la potencia volitiva. Este actuar voluntario es específico del hombre: él es el único agente que actúa por un fin. De hecho, Suárez afirma taxativamente que este modo de actuación, por fines, es exclusivo del hombre: no se halla ni en las criaturas irracionales, que no son capaces de elegir, ni en las racionales superiores (o en las racionales humanas en estado de separación del cuerpo), cuya voluntad ya está unida al bien de un modo necesario; ni siquiera se halla en Dios, en cuanto que en él su actuar y su conocer no se distinguen de su propia esencia.

En el comentario de 1579, Suárez ya había admitido que, propia y perfectamente, solo el actuar humano es por fines, afirmando a la vez que, dado que la causalidad del fin tiene su fundamento en el intelecto, también los seres inanimados y los vivientes no racionales se mueven por un fin, aunque en estos casos el fin sólo sea conocido por una inteligencia superior que a todos gobierna. De hecho, todo lo creado está sometido al orden de la inteligencia de Dios con respecto al mundo, a la cual se llama providencia y cuya función es dirigir todas las cosas a sus propios fines ${ }^{57}$. En el comentario de 1628, va

56 SuÁRez, F., Trac. I, Disp. I, sect. I, § 1, p. 1: «Primum omnium statuendum est, finem et causalitatem ejus, qualiscumque illa sit, proprie suum locum habere in voluntate humana, et in actibus, seu effectibus ejus, quod est certissimum». Itálico nuestro.

57 Ya en el MDB Suárez reconocía que el argumento de la finalidad universal deducido del orden cósmico es filosóficamente limitado, pues ya los antiguos filósofos, ante el mismo hecho del movimiento del cosmos, deducían que la naturaleza no se orientaba por ningún tipo de finalidad. Explica ahí Suárez que Tomás adhiere a la causalidad final universal de Aristóteles porque sabe que la naturaleza tiene un autor, o sea, asumiendo el dado teológico de la creación del mundo por Dios. Más adelante llega a decir que, sustraído el argumento teológico, no hay ningún motivo para deducir que «todo se mueve por un fin» o que la naturaleza se rige por algún tipo de orden (Cfr. MDB, 15-16, pp. 22-24). 
matizando el adagio aristotélico omne agens agit propter finem hasta el punto de poder decirse que lo rechaza efectivamente: no todo agente actúa por fines.

Actuar por fines —es ésta la tesis definitiva de Suárez y es una tesis de filosofía del hombre- es propio tan solo del hombre. Los demás modos de actuar son específicos de la naturaleza y su característica es la necesidad: es lo que ocurre en el actuar de los seres inánimes y de los vivientes no racionales. La necesidad es también lo que caracteriza el actuar de los agentes libres que viven ya en la pose del fin último, es decir, los bienaventurados. Pero esta necesidad, que garantiza la perpetuidad de la bienaventuranza, no tiene su origen en la naturaleza sino en un don sobrenatural que se llama gracia ${ }^{58}$.

Como antes en el MDB, lo que está en causa en la disputación que ahora analizamos es identificar exactamente en qué consiste, para el actuar humano, ser causado por un fin, o sea, moverse hacia él. Pues si toda causa es un principio de acción, ¿en qué se distinguen el modo de actuar de la causa eficiente y el de la final, siempre en el caso de los agentes libres? Si la causa final mueve el hombre a actuar libremente, y toda causa es principio de movimiento, ella tiene que actuar sobre la voluntad: ¿cómo puede tal causa mover no esta, sino otra potencia, que es el intelecto? Pues en ese caso, la causa final, en el caso del agente libre, sería extrínseca a la voluntad, comprometiendo su libertad y trasfiriendo el centro del actuar moral a una potencia no libre ${ }^{59}$. Solucionando estas dos cuestiones centrales de filosofía del hombre y encontrando el principio responsable por la acción causal del fin sobre el agente libre, será posible definir exactamente qué significa actuar finaliter.

Como soluciones posibles para estas cuestiones, Suárez discute dos opiniones, que rechaza por considerar que son modos extremos de comprender la causa final en tanto que motor del agente libre. Una primera considera que la causa final no mueve realmente al agente, pues no ejerce ninguna actividad sobre la voluntad. Tal causalidad consistiría en una moción distinta de la que ocurre en la voluntad y en virtud de la cual ésta se dirigiría para ese fin. Pero, si así es, esta supuesta causa no ejerce en la voluntad ninguna causalidad, que se mueve hacía el fin sólo como efecto de un otro movimiento distinto de ella.

58 No es aquí posible más que enunciar la importancia de las encendidas controversias de esta época sobre gracia, libre arbitrio, predestinación, ni, por mayor razón, desarrollar los argumentos con los cuales los sistemas teológicos de la escolástica tardía intentan compatibilizar esta aparente contradicción: la gracia sobrenatural hace que la libertad de las criaturas se adhiera necesariamente al fin último sobrenatural de los que libremente lo aman y que es Dios.

59 Sobre el modo como Suárez construye su teoría del actuar voluntario, sobre las ligaciones entre su doctrina, el intelectualismo tomista y el voluntarismo escotista vid. el agudo y consistente análisis de PINK, Th., «Suárez, Hobbes and the scholastic...», ob. cit., pp. 128-135. Pink comenta que cree que esta es una doctrina de escuela, y no específicamente la posición de Suárez. Esta es también nuestra percepción, pero esa labor todavía está por hacer: identificar las doctrinas comunes de la escuela jesuita y, a la vez, mostrar las diferencias específicas de las posiciones de cada autor, lo que hablaría del espacio concedido a la libertad de interpretación. 
Esta opinión no explica de qué modo la voluntad es movida por un fin y por ello debe rechazarse ${ }^{60}$. La segunda opinión es esta: «que se diga que el fin es aquello por lo algo se hace, es solamente una denominación extrínseca en el mismo fin, a partir del hecho de que alguna otra cosa se ordena a él: por lo tanto eso no basta para la causalidad propia del fin ${ }^{61}$. Esta opinión se aproxima a la anterior, ya que ambas colocan el locus finis en la potencia intelectiva. Suárez rechaza igualmente esta opinión, pues que el fin se llame causa por denominación extrínseca (es decir, solamente por su presencia formal en el intelecto), no basta para la causalidad propia del fin, porque en este caso el agente no se dirige al fin como tal, sino a la representación mental de éste.

Para que se pueda hablar de causalidad del fin en el agente humano, el fin tiene que mover real y directamente a la voluntad pues es por relación a este movimiento que ella elige libremente. En cambio, el modo de moverse de los agentes naturales supone siempre un movimiento originado por algo en acto, que actúa sobre una pasividad proporcionada. Al menos es así como Aristóteles explica el movimiento de los cuerpos naturales.

En cambio, Suárez insiste en que la voluntad es una facultad del alma intelectiva del hombre y que ésta última es un principio vital intrínseco que unifica la substancia humana. Ahora bien, en cuanto principio intrínseco de movimiento, su actuar se origina interiormente y a partir de sí. No puede, por consiguiente, ser actualizado por una realidad distinta de él. De hecho, en cuanto principio vital, el alma humana es potencia activa. Eso viene a decir que el actuar de sus facultades no puede ponerse en acto por una realidad otra de ellas mismas, como acontecería si fueran movidas por algo extrínseco a ellas. Ese sería el caso si la voluntad fuera puesta en marcha por una cualquier formalidad conceptual, pues ella no es la facultad de producir conceptos.

En el movimiento de causalidad del fin, la proporcionalidad entre este y la voluntad ocurre por parte del fin, en el bien que le es inherente y por parte de la voluntad en el movimiento autónomo que realiza hacia él. El bien que mueve a la voluntad como fin es, por lo tanto, querido por sí mismo y poseído voluntariamente.

Tal como lo entiende Suárez el movimiento en el que consiste la causalidad final tiene lugar en la voluntad y en ella es una moción efectiva, específica de los agentes libres. Esta moción se distingue de la que ocurre en el movimiento físico, ya que la voluntad es una potencia inmaterial. Y así se dice que la causa final mueve a la voluntad por una cierta analogía con el movimiento

60 SuÁrez, F., Tract. I, I, I, 2, p. 1: «Prima est causalitatem finis non consistere in motione aliqua respectu humanae voluntatis, sed in hoc solum, quod effectus, qui a voluntate progreditur, in aliquid ut in finem ordinetur, ita ut esse finem nihil aliud sit, quam esse id, cujus gratia aliud sit».

61 Ibid., I, I, 4, p. 2: «quod finis dicatur esse id, cujus gratia aliquid fit, solum est denominatio quaedam extrinseca in ipso fine; ex eo quod aliquid aliud ordinatur ad ipsum: ergo non satis est hoc ad causalitatem propriam finis». 
en los cuerpos naturales o, como dice Suárez, en la voluntad moverse se dice metaphorice. Como dice Suárez, esta es una doctrina común en la cual todos autores están de acuerdo ${ }^{62}$. Sin embargo, no todos la interpretan del mismo modo $^{63}$. Suárez rechaza muy claramente la interpretación de matriz tomista, al afirmar que el juicio del intelecto no es la causalidad del fin ${ }^{64}$. Y explica por qué no puede aceptarse. El acto del juicio no pone la voluntad en acto, no siendo más que una influencia próxima de ese movimiento. Pero la causalidad del fin supone que algo sea causado en la voluntad como acto primero, pues solo así se da una causalidad real ${ }^{65}$.

¿En qué consiste, según Suárez, esta moción metafórica? Consiste en un cierto movimiento, acto u afección, distinto y nuevo, originado en la voluntad por la fuerza del bien, y que consiste en moverse hacia el fin. Ese movimiento se caracteriza por la apetencia generada en ella, por el bien en cuanto bien, y no en cuanto representado por el intelecto ${ }^{66}$.

Si lo que es propio de toda causa es producir movimiento, en el caso de los agentes libres esa moción se origina por el fin en la voluntad. Tal movimiento no puede ser causado por el intelecto o por el conocimiento de la razón de fin, como proponía Tomás. Pues a ser así, no es el fin que ejerce causalidad en la voluntad sino su representación formal. Inversamente, Suárez considera que el bien mueve la voluntad produciendo en ella un acto intrínseco, verdadero y propio, diferente del movimiento «que se dice que hay en el hombre que conoce el fin y su bondad antes de que la voluntad se mueva con propio movimiento ${ }^{67}$, o sea distinto del movimiento propio del acto de entender el cual ocurre en la potencia cognitiva. Es cierto que el conocimiento del fin antecede al movimiento de la voluntad. Sin embargo, este movimiento de la voluntad en dirección al

${ }_{62}$ Ibid., I, I, 4, p. 2: «(...) auctores omnes ponunt causalitatem finis in motione metaphorica respectu nostrae voluntatis».

${ }_{63}$ La opinión que rechaza Suárez en el Trac. I, I, 5, p. 2, es la explicada en el Comentario Conimbricense à Física de Aristóteles II, c. 7, q. 21, a. 1 (1599), cit. por Amândio Coxito, «Natureza, Arte, Acaso e Finalidade na Física do Curso Conimbricense», Revista Filosófica de Coimbra (2003) 62-63: «(...) há duas espécies de moção: uma própria, que corresponde a uma verdadeira e genuína ação (e que melhor designaríamos, em sentido genérico, por "movimento"), como quando o fogo aquece a água; e outra imprópria ou figurativa ("translatitia"), "segundo a qual mover se diz daquilo que, incutindo um amor para consigo, atrai e aproxima de si a alma”. É nesta moção figurativa ou metafórica — pela qual uma coisa, enquanto apreendida pela inteligência é proposta à vontade como objeto de desejo e de amor - que consiste a causalidade final. (...) um determinado fim, apreciado como um bem, provoca uma apetência que, por sua vez, incita a vontade a procurar os meios para atingi-lo».

${ }^{64}$ SuÁrez, F., Trac. I, I, I, 5, p. 2: «Haec vero nec intelligi possunt, nec satisfacere; (...) judicium intellectus non est causalitas finis».

65 Ibid., "quia realis causalitas debet ad aliquid reale haberi, alias nihil esset: sed si in voluntate nulla est res nova, nec operatio aliqua, vel affectio, nihil intelligi potest, quod a fine causarum sit: ergo nec intelligi potest causalitas finis in actu secundo».

66 Cfr. Ibid., I, I, 5, p. 2. Este párrafo es central para entender por qué, para Suárez, la cognitio finis no es causa final del actuar libre de hombre.

67 Vide n. 69. 
fin es realmente distinto del conocimiento del fin y de su conveniencia para el hombre ${ }^{68}$.

En definitiva, la doctrina de Suárez sobre la causalidad del fin se puede explicar a la luz de dos principios fundamentales. En primer lugar, solo hay causalidad del fin cuando hay un acto producido directamente en la voluntad del agente libre por ese principio o causa, pues si no se produce algo en acto, no habrá fin en acto $^{69}$. La causalidad final es una verdadera moción que ocurre en la voluntad, en acto ejercido, y no basta para explicar esta causalidad el movimiento causado en la voluntad a partir de otro principio intermediario, como sea el juicio o deliberación sobre la conveniencia del bien conocido. Como dice Suárez, «en la voluntad antes de la acción de la voluntad no hay causalidad del fin $»^{70}$.

En segundo lugar, la causalidad del fin no es sino «la misma acción que procede a la vez de la voluntad en el género de causa eficiente, y del fin en el suyo ${ }^{71}$. Teniendo en mente la teoría del concurso causal o de las causas concomitantes propuesta por Escoto, Suárez explica el movimiento de causalidad final como una acción co-causada. Esta se puede describir como una acción inmanente en la que la voluntad, como potencia activa, actúa como causa eficiente, mientras el fin deseado actúa como causa final. No se confunden ambos principios, el fin y el movimiento de la voluntad hacia él, sino que operan simultáneamente. La acción humana libre no se da sin el concurso concomitante de ambos. En cuanto potencia activa, la voluntad es causa eficiente del ato que se hace por el fin, siendo este el que, en su bondad intrínseca, la atrae y determina a tal acto.

La causalidad final se ejerce cooperativamente. Como dice Suárez, en la voluntad su acción es su concurso. Su operación depende intrínseca y esencialmente de estos dos principios: la potencia volitiva y el fin propuesto. El movimiento hacia el fin procede de la voluntad: ella es causa eficiente de ese movimiento. Pero en cuanto procede del fin, es decir, en cuanto el fin es un género de causa, la causalidad final es la moción actual de la voluntad hacia él. Explica aún Suárez que no conviene distinguir en esa acción dos razones o modos, ya que por sí misma y esencialmente esta causalidad exige la doble relación.

68 Ibid., pp.2-3: «illa excitatio, quae dicitur esse in homine cognoscente finem et bonitatem ejus antequam voluntas proprio motu moveatur, nihil aliud est revera, quam cognitio et judicium intellectus; nam in voluntate nihil de novo positum est, quod ante non esset: sed judicium intellectus non est causalitas finis, ut per se constat, sed potius est approximatio finis, ut [3] causare possit: ergo non potest in hoc solo consistere causalitas finis».

69 Ibid., I, I, I, 7, p. 3: «si ergo nihil actu fit, non est actu finis». Prosigue el texto: «si el eficiente en acto no produce el acto, nada produce; y por tanto nada se hace por un fin; luego, del primer al último, antes del acto del agente no hay causalidad del fin». [«Si autem efficiens actu non efficit actu, nihil fit: et consequenter nihil fit propter finem : ergo, de primo ad ultimum, ante actum agentis non est causalitas finis.]

70 Ibid., «(...) in voluntate ante actionem voluntatis non est causalitas finis (...)».

71 Ibid., I, I, I, 8, p. 3: "Causalitas finis in voluntate non est res aliqua, nec modus distinctus ab actu et actione voluntatis: sed est ipsamet actio, quae simul est et a voluntate in genere causae efficientis, et a fine in suo genere, scilicet, trahente, et determinante voluntatem ad talem actum». 
Entre la potencia volitiva y la potencia cognoscitiva existe por lo tanto esta diferencia: el concurso de la potencia cognitiva pertenece a la causa efectiva y el de la voluntad a la causa final, distinción ésta que tiene su origen en los propios principios de la operación de tales potencias. A su vez, aunque sea una operación correlativa entre el fin y la voluntad, el actuar libre por un fin es una única y misma acción que «depende intrínseca y esencialmente de estos dos principios, a saber, de la potencia y del fin propuesto ${ }^{72}$.

Suárez saca dos consecuencias de este análisis de la causalidad final como acción correlativa del fin y de la potencia volitiva. Por una parte, «la causalidad del fin sólo tiene lugar en los agentes por medio del conocimiento» ${ }^{73}$, ya que supone el conocimiento del bien y de su conveniencia para la potencia. Dicho de otro modo, sólo los agentes intelectuales creados son sujetos de finalidad. Con esta conclusión, Suárez excluye a los seres irracionales de la causalidad final. Por otra parte, excluye el actuar de Dios de este modelo de causalidad. Pues en Dios no hay esta distinción entre potencias y objetos adecuados, entre mociones y conquista del bien. En el actuar de Dios la unidad entre conocer y querer es plena, a punto de identificarse con su esencia ${ }^{74}$.

Suárez deja patente que la causalidad final es una verdadera y propia moción de la voluntad que produce un verdadero acto autónomo e intrínseco del sujeto humano, como totalidad substancial e individual. Esta moción de la voluntad, porque es efectivamente libre, es origen y fundamento de la moralidad. Esenciales para su teología del fin último del hombre, estas conclusiones sobre la causalidad final del agente libre son importantes principios de la filosofía del hombre construida por Súarez para fundamentación racional de su teología moral.

\section{ConCLusiones}

En este trabajo nos hemos ocupado de explorar la cuestión sobre la causalidad del fin en los agentes libres en dos comentarios de Francisco Suárez a la I-IIae qq.1-5: un comentario de juventud, subsistente en el ms. De

72 Así lo explica en el Trac., I, I, 8, p. 3: «(...) sicut in potentia cognoscitiva actio ejus natura sua pendet a potentia, et ab objecto ut movente potentiam, ita suo modo actio voluntatis, in potentia autem cognoscitiva eadem actio ut est a potentia est concursus ejus ad talem actum, et ut est ab objecto est similiter causalitas ejus: ergo eodem modo in voluntate actio ejus, quia intrinsece, et essentialiter pendet ab his duobus principiis, scilicet a potentia et a fine proposito, ut est effective a voluntate, est concursus ejus: ut vero est a fine in suo genere causae, est motio actualis ejus (...)» Un lugar paralelo se encuentra en Disputationes Metaphysicae XVIII, 8, 39-40.

${ }_{73}$ Ibid., trac. I, I, I, 9, p. 3: «causalitatis finis tantum habere locum in agentibus per cognitionem, nam alia agentia non possunt a fine moveri».

${ }_{74}$ Ibid., I, I, I, 10, p. 3: «hanc causalitatem finis, prout exercetur in voluntate, non reperiri proprie in Deo, nec in voluntate ejus: sed solum in voluntate creata, quae per actionem propriam, et actum a se distinctum movetur in finem». 
beatitudine, fechado en 1579, y el tratado denominado De ultimo fine hominis, trabajo de madurez publicado en 1628 por Baltasar Álvares. El análisis aquí elaborado de estos dos documentos y de la cuestión indagada se ha asumido como instrumento heurístico con dos objetivos principales. En primer lugar, presentar el manuscrito del 1579 el cuál, por su condición de inédito es per se un instrumento novedoso e importante para conocer mejor la obra y doctrinas de Suárez, concretamente sobre filosofía del hombre y psicología moral. En segundo lugar, evidenciar la teoría de Suárez sobre la causalidad del fin en los agentes libres. Analizando su explicación al respecto en el comentario del ms de 1579 se pretendió identificar su doctrina en este período de juventud y verificar hasta qué punto su exposición es compatible con la doctrina de Tomás de Aquino, una vez que datan de ese período las acusaciones de anti-tomismo recibidas por Suárez de parte de otros jesuitas. Analizando el mismo tema en el comentario del 1628 se tuvo en mira identificar los fundamentos filosóficos de la doctrina de Suárez, ahora consolidada, con respecto a la teoría de los fines y de su influencia en el agente libre.

En el comentario del 1579, la doctrina de Suárez sobre la causalidad de los agentes libres se puede resumir en los siguientes puntos: actuar por un fin es actuar por el conocimiento del fin. Eso puede ocurrir de dos modos: o bien por medio de la inteligencia gobernante creadora y universal: y es así que todos los seres no racionales, sean o no vivientes, actúan por un fin; o bien por el conocimiento de la razón del fin, lo que ocurre en las creaturas racionales, entre las cuales se encuentra el hombre. La causalidad del fin significa, para un agente, ser el principio y el fin del actuar. Y eso es lo que pasa con el hombre cuando elige libremente: pone en acción su facultad de la razón y voluntad, o sea, el libre arbitrio. Esta es la tesis explicada por Suárez y coincide con la doctrina de Tomás de Aquino al respecto. Sin embargo, en su exposición de la doctrina tomista Suárez discute las tesis de otros teólogos, incluso tesis no tomistas, y manifiesta alguna hesitación sobre lo que realmente hubiera querido decir Tomás. A veces incluso es crítico con relación a algunas explicaciones del Aquinate, apuntándole equivocaciones. Otras veces, expone la doctrina de Tomás pero al hilo de su explicación, por veces no demasiado clara, no queda evidente la proximidad y dependencia con relación al doctor medieval. Si estas diferencias y matices tienen entidad suficiente para sustentar las críticas arriba mencionadas es algo que dejamos al lector.

En el comentario póstumo, editado por Baltasar Alvares en 1628, la doctrina de Suárez sobre el modo como el fin es causa para el agente libre es bastante elaborada y rica de contenidos. Se puede incluso entender cómo el desarrollo madurado de lo que en 1576 estaba implícito en sus hesitaciones, advertencias y sentencias. El principal cambio ocurre en el modo de concebir el actuar de las potencias humanas de conocer y querer, sea en la interrelación entre ambas, sea con respecto a las potencias corporales y anímicas, sea con relación a la percepción de los objetos del mundo externo por la sensibilidad externa e interna del hombre. O sea, en el comentario del 1628, del que aquí no pudimos explicar más que una pequeñísima cuestión, Suárez sustenta su teología moral en una 
verdadera y propia doctrina sobre lo que es el hombre, sobre el modo como en él se relacionan cuerpo, alma y mente racional y sobre lo que es actuar libremente.

Básicamente, su doctrina se fundamenta en los siguientes principios: el hombre conoce el fin y el bien por medio del intelecto. Hasta aquí, mantiene la posición de Tomás, dado que sin conocer previo de la conveniencia del bien no hay libertad. Sin embargo, el conocimiento no basta para el actuar libre ni es su causa final. Pues puede bien ocurrir que el hombre conozca el bien, delibere sobre los medios para alcanzarlo y no actúe en vista de él o actúe de modo distinto a la deliberación. La causalidad del fin por lo tanto, no es un acto del intelecto, sino de la voluntad. Es la voluntad que, como potencia de un principio vital inmanente que es el alma racional, se mueve a si directamente por la fuerza atractiva del bien, supuesto el conocimiento de su conveniencia. Esta doctrina sobre la causalidad del fin está próxima de la concepción escotista de la voluntad de indiferencia, como también lo está la concepción desarrollada por Suarez de las relaciones entre intelecto y voluntad, y sobre el modo como concurren concomitantemente para el actuar humano.

El estudio de los comentarios filosóficos y teológicos producidos en la escolástica peninsular a lo largo del siglo XVI es válido en cuanto tal, en la medida en que las doctrinas ahí explicadas permiten esclarecer cómo los conceptos filosóficos de la tradición antigua y medieval fueron recibidos y transformados, en un contexto histórico y doctrinal que es como la puerta de entrada para la modernidad. En el caso particular de Suárez, como autor mayor de este período, y en particular en los aspectos que referenciamos en este artículo, se pueden identificar con bastante claridad teorías que, leídas y asimiladas por los filósofos del XVII sirven de fundamento a tesis clave de autores de la modernidad y del iluminismo, con influencias claras sobre todo en filósofos que se formaron y actuaron en Alemania.

Una de las tesis postuladas por Suárez, y en esto se demarca del tomismo, es la de que el hombre es el único ser que se mueve por fines, consistiendo en esto el actuar específicamente humano. Este es el centro de la teoría de la causalidad final del agente libre, como la propone Suárez. Sólo el hombre construye su camino hacia la felicidad, que es su fin último, y su voluntad es puesta en marcha por la fuerza atractiva del bien, al que se dirige por sí misma y a partir de sí misma. Es así porque la voluntad es un principio vital inmanente cuya autonomía en dirección al bien caracteriza el hombre. Por lo tanto, el principio último de la moralidad es la acción del principio inmanente que es la voluntad, movido por la propia fuerza del fin en cuanto bien. De esta afirmación, hacia esta otra, según la cual la autonomía es el fundamento de la dignidad de la naturaleza humana y de toda naturaleza racional, como escribe Kant en su Fundamentación de la Metafísica de las Costumbres, hay seguramente un itinerario conceptual, pero la doctrina de Suárez que aquí evidenciamos es puerta abierta para esta concepción del hombre.

Igualmente, la idea kantiana según la cual la naturaleza es el reino de la necesidad no está lejos de lo que Suárez viene a decir. En el comentario del 1579, al presentar la teoría tomista de la causalidad final universal fundada en 
el conocimiento indirecto del fin, en el caso de los irracionales, dice que la teoría solo se sustenta en un horizonte teológico, o sea, si se tiene en cuenta la existencia de un principio criador y gobernador que es Dios. Pues sin eso, aún los mismos filósofos antiguos sustentaban, a partir del movimiento, la inexistencia de Dios y de una dirección teleológica extrínseca a la constitución misma de los cuerpos materiales. Suárez afirma así que, sin el principio teológico del creacionismo, la naturaleza puede ser comprendida como ciega e irracional. Retirando al sistema su presupuesto teológico, surge la dicotomía entre una naturaleza ciega en la que reina la necesidad y una naturaleza humana que se caracteriza por actuar libremente por fines. Y de nuevo nos viene en mente Kant, cuando, en la Crítica de la Razón Pura dice abiertamente que la naturaleza solo tiene de racional aquello que el hombre le añade cuando construye ciencia.

Otra conclusión de esta misma teoría de la causalidad final de los agentes libres tal como Suárez la concibe es la de que no hay hombres amorales. Dicho de otro modo, la vivencia ética es propia del hombre, justamente en el sentido que le confería el éthos primigenio ( $\hat{\eta} \vartheta \circ$ ) referenciado por los filósofos antiguos, como el hábitat o la morada que permite el hombre resguardarse del estado de naturaleza y configurar su ser respecto al mundo. En este exacto sentido Heidegger construye su noción que podríamos denominar «espacial» de la ética: «la estancia del hombre contiene y preserva el advenimiento de aquello que le toca al hombre en su esencia» ${ }^{75}$. No se pretende, con estas meras referencias intertextuales aquí dejadas a modo de conclusión, afirmar la dependencia directa de estos autores con relación a la doctrina de la causalidad del fin de Suarez. Están hoy disponibles muchos estudios, algunos de los cuales, referenciados a lo largo de este artículo, demuestran de modo detallado estas relaciones, sus itinerarios históricos y conceptuales. Lo que sí siempre se verifica, cuando nos acercamos a estos y otros textos de Suárez y de sus contemporáneos, es, por una parte, la riqueza de fundamentación teórica de sus convicciones y por otra, lo lejos que todavía estamos de tener una visión adecuada de la historia de la filosofía sobre todo en lo que se refiere a las conexiones entre la filosofía escolástica del XVI y las teorías filosóficas del periodo que designamos como modernidad.

Universidad Loyola Andalucía (España)

rcolmenarejo@uloyola.es

Rosa Colmenarejo Fernández

Universidade do Porto (Portugal)

pvsilva@letras.up.pt

Paula Oliveira e Silva

[Artículo aprobado para publicación en enero de 2018]

75 Heidegger, M., Carta sobre el Humanismo, trad. H. Cortés y A. Leyte, Alianza Editorial, Madrid 2000 p. 74. 